\title{
Affinity Binding of the Cartilage Proteoglycan Protein- Keratan Sulfate Core to Immobilized Hyaluronic Acid
}

\author{
James E. Christner, Martin L. Brown, and \\ Dominic D. DziewiatKowski \\ Departments of Oral Biology and Biological Chemistry and The Dental Research Institute. \\ The University of Michigan, Ann Arbor, Michigan 48109
}

Received October 28, 1977

\begin{abstract}
The protein-keratan sulfate core of bovine nasal cartilage proteoglycan was purified by affinity chromatography on a column of immobilized hyaluronic acid. The hyaluronic acid was immobilized by reaction with a hydrazido-alkyl derivative of Sepharose in the presence of borohydride. Proteoglycan was digested with chondroitinase $\mathrm{ABC}$ and the entire mixture was passed over a column of the Sepharose-hyaluronic acid maintained at $4^{\circ} \mathrm{C}$. After the digested chondroitin sulfate chains were washed from the column, the bound protein-keratan sulfate corc was cluted with $4 \mathrm{M}$ guanidinium chloride. The protein-keratan sulfate core interacts with the affinity matrix through its hyaluronic acid binding site as shown by the inhibition of binding by free hyaluronic acid and hyaluronic acid decasaccharide.
\end{abstract}

The proteoglycan molecule from bovine nasal cartilage is composed of a protein core of molecular weight 200,000 to which many chondroitin sulfate and keratan sulfate chains are covalently attached at their reducing ends $(1,2)$. In hyaline cartilage, the extracellular proteoglycans exist mainly as large aggregates (3-7). The aggregates dissociate in concentrated solutions of electrolytes thereby allowing their ready extraction from connective tissue (4). Reassociation of the aggregate components takes place in vitro when the dissociative solute is removed or sufficiently diluted $(4,8)$. The extracted proteoglycans can be isolated in aggregated or monomeric form by density gradient centrifugation under associative or dissociative conditions, respectively $(8,9)$.

Recently, details of the aggregation process have been elucidated $(5,10-13)$. Hardingham and Muir (10) demonstrated that cartilage proteoglycans interact in vitro with $\mathrm{HA}^{1}$ producing a large increase in hydrodynamic volume as judged by gel chromatography and viscosimetry. This complex appears to consist of many proteoglycan molecules bound at

1 Abbreviations used: HA, hyaluronic acid; Sepharose-HA, hyaluronic acid covalently attached to adipic acid dihydrazide-substituted Sepharose 2B; $\mathrm{GuHCl}$, guanidinium hydrochloride; core, protein-keratan sulfate core prepared from chondroitinase ABD-digested proteoglycan. 
intervals along the HA chain. Each proteoglycan molecule contains one HA-binding site located near one end of the protein core $(10,11)$. Two low molecular weight proteins (link proteins) found in extracts of cartilage stabilize the aggregates $(11,12)$ presumably by interaction with proteoglycan and HA. The features of these interactions are summarized in the model for the proteoglycan-HA-link protein complex proposed by Heinegård and Hascall (13) and by Rosenberg et al. (14).

The binding site on the proteoglycan molecule is specific for HA. Cartilage proteoglycans do not interact with polyanions such as dextran sulfate, sodium alginate, DNA, or chondroitin sulfate (10) or chondroitin (11). Furthermore, the binding site exhibits specificity for polysaccharide chain length. The HA decasaccharide, with $\mathrm{N}$-acetylglucosamine at the reducing end, is much more effective than the corresponding octasaccharide in displacing the intact $\mathrm{HA}$ chain from the proteoglycan $(11,15)$.

The fact that cartilage protenglycan interacts specifically with HA makes possible its isolation and purification by affinity chromatography. In this report, we describe the preparation of an affinity matrix comprised of HA covalently attached to agarose beads. The protein-keratan sulfate core, prepared by removal of chondroitin sulfate chains from bovine nasal cartilage proteoglycan by the action of chondroitinase, binds to the immobilized HA and can be eluted with concentrated solutions of GuHCL. Also, immobilized HA can be used as a convenient binding reagent to study the interaction between core and HA. Some of these results have been reported in a preliminary communication (16).

\section{MATERIALS AND METHODS}

Materials. Sepharose 4B and Sepharose 2B were obtained from Pharmacia, Inc. (Piscataway, N. J.), sodium cyanoborohydride from Aldrich Chemical Co. (Milwaukee, Wis.), adipic acid dihydrazide from Sigma Chemical Co. (St. Louis, Mo.), purified bovine testicular hyaluronidase (EC 3.2.1.35) from Worthington Biochemicals Corp. (Freehold, N. J.), chondroitinase $\mathrm{ABC}$ (EC 4.2.2.4) and crystalline bovine serum albumin from Miles Laboratories (Elkhart, Ind.), and cyanogen bromide from Eastman Organic Chemicals (Rochester, N. Y.). Proteoglycans were isolated from bovine nasal septal cartilage by a procedure described by Oegema et al. (17). The protein-keratan sulfate core of proteoglycan was prepared as described by Hascall and Heinegård (11). Umbilical cord HA (Grade I) was purchased from Sigma Chemical Co., and rooster comb HA was isolated by the method of Swann (18). The molecular weight of the material from umbilical cord, as determined viscosimetrically (19), was $7.8 \times 10^{5}$ and that from rooster comb was $1.6 \times 10^{6}$. Oligosaccharides were prepared by partially digesting $\mathrm{HA}$ with testicular hyaluronidase and isolated by gel chromatography on a standardized column of Sephadex 
G-50 (Superfine) according to the method of Hascall and Heinegård (11). Lactoperoxidase (EC 1.11.1.8) was obtained from Worthington Biochemical Corp. (Freehold, N. J.) and was insolubilized according to the method of David and Reisfeld (20). Protein-keratan sulfate core was radioiodinated with insoluble lactoperoxidase by the method described by David and Reisfeld (20) for preparing low specific activity ${ }^{125}$ I-iodinated protein. The specific activity of the preparation was $0.7 \mu \mathrm{Ci} / \mu \mathrm{g}$ of protein. Highly purified chondroitin, which was a generous gift of Dr. J. A. Cifonelli (University of Chicago, Chicago, Ill.) was obtained from Dr. I. J. Goldstein, University of Michigan, Ann Arbor, Michigan.

Analytical procedures. Uronic acid and protein were determined by automated methods (21). The amino acid content of proteins was determined by the method of Spackman et al. (22) except that titanous chloride was used as the reducing agent in the ninhydrin reagent. The proteins were hydrolyzed at $110^{\circ} \mathrm{C}$ in $6 \mathrm{M} \mathrm{HCl}$ for $24 \mathrm{~h}$ in evacuated tubes. Hexosamines were determined with an automated amino acid analyzer after hydrolysis at $100^{\circ} \mathrm{C}$ in $4 \mathrm{M} \mathrm{HCl}$ for $16 \mathrm{~h}(23)$.

Preparation of insolubilized HA. Separose $2 \mathrm{~B}$ was reacted with cyanogen bromide and coupled with adipic acid dihydrazide by the method described by Wilchek and Miron (24). The hydrazido-Sepharose was added to an equal volume of $0.1 \mathrm{~m}$ sodium acetate, $\mathrm{pH} 5$, containing $0.5 \mathrm{mg}$ of rooster comb $\mathrm{HA} / \mathrm{ml}$ and the mixture was agitated by gentle shaking at $4^{\circ} \mathrm{C}$ for 16 to $20 \mathrm{~h}$. The reacted Sepharose was washed on a fritted-glass filter with $10 \mathrm{vol}$ of $0.2 \mathrm{M} \mathrm{NaCl}$ and $10 \mathrm{vol}$ of water and then was resuspended in an equal volume of $0.1 \mathrm{M}$ sodium acetate, $\mathrm{pH} 5$. Sodium cyanoborohydride $(19 \mathrm{mg} / \mathrm{ml}$ of Sepharose) was added and the mixture was stirred for $1 \mathrm{~h}$ at room temperature. The substituted gel beads were washed on a fritted-glass filter with $20 \mathrm{vol}$ of water, $20 \mathrm{vol}$ of $0.2 \mathrm{M}$ $\mathrm{NaCl}$, and again with water. The washed beads were agitated at $4^{\circ} \mathrm{C}$ in $4 \mathrm{~m} \mathrm{GuHCl} / 0.05 \mathrm{~m}$ sodium acetate, $\mathrm{pH} 5.8$, for $16 \mathrm{~h}$ before being analyzed for coupled HA content or used for affinity chromatography. The Sepharose-HA was stored at $4^{\circ} \mathrm{C}$ in $4 \mathrm{M} \mathrm{GuHCl} / 0.05 \mathrm{M}$ sodium acetate, $\mathrm{pH} 5.8$.

Analysis of bound HA. The concentration of the immobilized HA was estimated by determining the glucosamine or uronic acid content of the substituted beads. To determine the glucosamine, Sepharose-HA beads were washed with water on a fritted-glass filter funnel and the excess water was removed by suction. Portions $(250 \mathrm{mg})$ of the moist beads were hydrolyzed in $1 \mathrm{ml}$ of $4 \mathrm{M} \mathrm{HCl}$ in sealed tubes at $100^{\circ} \mathrm{C}$ for $16 \mathrm{~h}$. The hydrolysates were filtered through glass wool and evaporated to dryness in a flash evaporator at $45^{\circ} \mathrm{C}$. Water was added to the residue and removed by evaporation several times to remove $\mathrm{HCl}$. The residue was dissolved in $1 \mathrm{ml}$ of water and fractionated on a $0.6 \times 5 \mathrm{~cm}$ column of Dowex $50 \mathrm{~W}-\mathrm{X} 8\left(\mathrm{H}^{+}\right)$. After addition of the sample, the column was 
washed with $10 \mathrm{ml}$ of water and eluted with $10 \mathrm{ml}$ of $1 \mathrm{M} \mathrm{HCl}$. The $\mathrm{HCl}$ fraction was evaporated to dryness several times and the glucosamine was determined; unsubstituted hydrazido-Sepharose served as the control substance. To determine the uronic acid content, the washed beads $(250$ $\mathrm{mg}$ ) were suspended in $1 \mathrm{ml}$ of $0.1 \mathrm{M}$ sodium acetate $/ 0.15 \mathrm{M} \mathrm{NaCl}, \mathrm{pH} 5$, containing 350 turbidity-reducing units of hyaluronidase. The mixture was incubated with shaking at $37^{\circ} \mathrm{C}$ for 16 to $20 \mathrm{~h}$. The beads were sedimented by centrifugation and the uronic acid content of the supernatant solution was determined; again unsubstituted hydrazido-Sepharose served as the control.

Determination of the relative capacity of Sepharose $-H A$ to bind the protein-keratan sulfate core of proteoglycans. Core $(1 \mathrm{mg})$ in $1 \mathrm{ml}$ of $0.5 \mathrm{M} \mathrm{GuHCl} / 0.05 \mathrm{M}$ sodium acetate, $\mathrm{pH} 5.8$, was applied to a $0.6 \times 4 \mathrm{~cm}$ column of Sepharose-HA previously equilibrated with the same buffer. After washing the column with $4 \mathrm{ml}$ of the equilibration buffer, it was eluted with $5 \mathrm{ml}$ of $4 \mathrm{M} \mathrm{GuHCl} / 0.05 \mathrm{~m}$ sodium acetate, $\mathrm{pH} 5.8$. The core content of the eluate was estimated by measuring the uronic acid by a manual carbazole method (25) since solutions containing high salt concentrations cannot be analyzed by the automated procedure. The proteinkeratan sulfate core gives a positive carbazole reaction since digestion of proteoglycan with chondroitinase $\mathrm{ABC}$ leaves a residual glucuronic ccid-containing disaccharide at the nonreducing end of the linkage region saccharides (23).

Preparation of the protein-keratan sulfate core of proteoglycan and isolation by affinity chromatography. Proteoglycan from bovine nasal cartilage $(250 \mathrm{mg})$ contained in $10 \mathrm{ml}$ of $0.1 \mathrm{M}$ Tris- $\mathrm{HCl} / 0.1 \mathrm{M}$ sodium acetate, $\mathrm{pH} 7.3$, was incubated with 5 units of chondroitinase $A B C$ at $37^{\circ} \mathrm{C}$ for $3 \mathrm{~h}$. The digest was then cooled in ice and placed on a $1.5 \times 25 \mathrm{~cm}$ column of Sepharose-HA at $4^{\circ} \mathrm{C}$. The column was washed with at least 5 column vol of $0.5 \mathrm{M} \mathrm{GuHCl} / 0.05 \mathrm{M}$ sodium acetate, $\mathrm{pH} 5.8$, and then with 5 column vol of $4 \mathrm{M} \mathrm{GuHCl} / 0.05 \mathrm{M}$ sodium acetate, $\mathrm{pH} 5.8$. The effluent was monitored for uronic acid by a manual carbazole method (25). The uronic acid-positive material eluting in the $4 \mathrm{M} \mathrm{GuHCl}$ was dialyzed exhaustively against glass-distilled water and freeze-dried.

Binding of the ${ }^{125}$ I-labeled protein-keratan sulfate core to Sepharose$H A$. The reaction mixtures contained $40 \mathrm{mg}$ (moist weight) of Sepharose-HA and ${ }^{125}$ I-radioiodinated core $\left(2 \times 10^{4} \mathrm{cpm}\right)$ in $0.5 \mathrm{ml}$ of $0.05 \mathrm{M}$ sodium/phosphate $/ 0.15 \mathrm{M} \mathrm{NaCl}, \mathrm{pH} 7.0$, containing $0.01 \%$ bovine serum albumin. To determine their capability to displace labeled core from Sepharose-HA, varying amounts of competitors of HA were added in $50 \mu \mathrm{l}$ of water. The mixtures were agitated by shaking for varying periods of time. The beads were then sedimented by centrifugation and the radioactivities were determined in aliquots of the supernatant solutions. 


\section{RESULTS AND DISCUSSION}

\section{Coupling HA to Hydrazido-Sepharose}

The effect of reaction conditions on the yield of immobilized HA is summarized in Table 1 . The use of sodium cyanoborohydride for the reduction step increased the yield about $70 \%$ over that obtained with sodium borohydride. This result was expected since, at $\mathrm{pH} 5$, cyanoborohydride is more stable than borohydride (26). When reacted under the same conditions, about $84 \%$ more rooster comb HA than umbilical cord HA was attached to hydrazido-Sepharose $4 \mathrm{~B}$ but the core-binding capacities of the two materials were similar. The affinity matrix with the highest concentration of bound $\mathrm{HA}$ and core-binding capacity was obtained by coupling rooster comb HA to hydrazido-Sepharose $2 \mathrm{~B}$ using sodium cyanoborohydride as the reducing agent.

The results in Table 1 also show that to bind the HA in a stable manner, it is necessary to add borohydride, but only after the HA and the hydrazidoSepharose have reacted for a suitable period of time. Evidently, during the initial reaction period, reactive groups on the HA react slowly with the hydrazido-Sepharose to form a product which is stable to washing

TABLE 1

Effects of Reaction Conditions on the Yield of Immobilized Hyaluronic acid and the Capacity to Bind Protein-Keratan Sulfate Core ${ }^{\prime \prime}$

\begin{tabular}{clclcc}
\hline $\begin{array}{c}\text { Type of } \\
\text { Sepharose }\end{array}$ & $\begin{array}{c}\text { Hyaluronic } \\
\text { acid source }\end{array}$ & $\begin{array}{c}\text { Interaction } \\
\text { time before } \\
\text { reduction } \\
\text { (h) }\end{array}$ & $\begin{array}{c}\text { Reducing } \\
\text { agent }\end{array}$ & $\begin{array}{c}\text { Immobilized uronic } \\
\text { acid or } N \text {-acetyl- } \\
\text { glucosamine } \\
(\mu \mathrm{mol} / \mathrm{g})^{b}\end{array}$ & $\begin{array}{c}\text { Core-binding } \\
\text { capacity } \\
\text { (absorbance } \\
\text { at } 525 \mathrm{~nm})\end{array}$ \\
\hline 4B & Umbilical cord & 4 & $\mathrm{NaBH}_{4}$ & 0.069 & 9.6 \\
4B & Umbilical cord & 4 & $\mathrm{NaCNBH}_{3}$ & 0.116 & 11.0 \\
4B & Rooster comb & 4 & $\mathrm{NaBH}_{4}$ & 0.127 & 10.3 \\
2B & Rooster comb & 4 & $\mathrm{NaCNBH}_{3}$ & 0.318 & 16.2 \\
4B & Rooster comb & 0 & $\mathrm{NaBH}_{4}$ & 0.021 & 0.0 \\
4B & Rooster comb & 4 & None & 0.005 & 0.2 \\
\hline
\end{tabular}

${ }^{2}$ A mixture containing $2.5 \mathrm{mg}$ of $\mathrm{HA}$ and $5 \mathrm{ml}$ (settled volume) of hydrazido-Sepharose in $5 \mathrm{ml}$ of $0.1 \mathrm{M}$ sodium acetate, $\mathrm{pH} 5.0$, was mixed at $4^{\circ} \mathrm{C}$ for the indicated interaction time. The suspension was filtered and washed with 10 vol of $0.2 \mathrm{M} \mathrm{NaCl}$. For reduction with $\mathrm{NaBH}_{4}$ the derivatized Sepharose was suspended in $5 \mathrm{ml}$ of water and treated with three 50 -mg portions of $\mathrm{NaBH}_{4}$ over a 1-h period at $25^{\circ} \mathrm{C}$. For reduction with $\mathrm{NaCNBH}_{3}$ the Sepharose was suspended in $5 \mathrm{ml}$ of $0.1 \mathrm{M}$ sodium acetate $(\mathrm{pH} 5), 50 \mathrm{mg}$ of $\mathrm{NaCNBH}_{3}$ was added, and the mixture was stirred for $1 \mathrm{~h}$ at $25^{\circ} \mathrm{C}$. The beads were then washed and analyzed for bound HA and core-binding capacity as described in the text.

${ }^{b}$ Micromoles of uronic acid or $\mathrm{N}$-acetylglucosamine per gram of moist Sepharose-HA.

" Total absorbance units at $525 \mathrm{~nm}$ eluting in the $4 \mathrm{~m} \mathrm{GuHCl}$ solution. 
with $0.2 \mathrm{M} \mathrm{NaCl}$ and water. After reaction with borohydride, the Sepharose-HA bond is stable in the presence of $4 \mathrm{M} \mathrm{GuHCl}$. The labile intermediate could be a substituted hydrazone formed by the reaction of the aldehyde group at the reducing end of the HA polysaccharide chain with the hydrazide group on the Sepharose. The hydrazone would be reduced to the more stable substituted hydrazine in the presence of borohydride.

\section{Chromatography of Protein-Keratan Sulfate Core on Sepharose-HA}

The elution profile shown in Fig. 1 was obtained when $250 \mathrm{mg}$ of proteoglycan was digested with chondroitinase $\mathrm{ABC}$ and subjected to chromatography on Sepharose-HA. Approximately $20 \mathrm{mg}$ of material was eluted in the $4 \mathrm{M} \mathrm{GuHCl}$. The yield and amino acid composition are similar to those obtained by other workers for protein-keratan sulfate core purified from chondroitinase digests by exhaustive dialysis followed by gel chromatography and/or alcohol precipitation (1). The material eluting in $4 \mathrm{M} \mathrm{GuHCl}$ was further characterized as core by its ability to bind to HA. The affinity-purified core, when subjected to gel permeation chromatography using Sepharose $2 \mathrm{~B}$, eluted as a broad peak in the included volume (Fig. 2A). However, if it was combined with rooster comb HA and then fractionated on Sepharose $2 \mathrm{~B}$, the uronic acid and protein eluted at the void volume (Fig. 2B) suggesting that the core binds to HA with

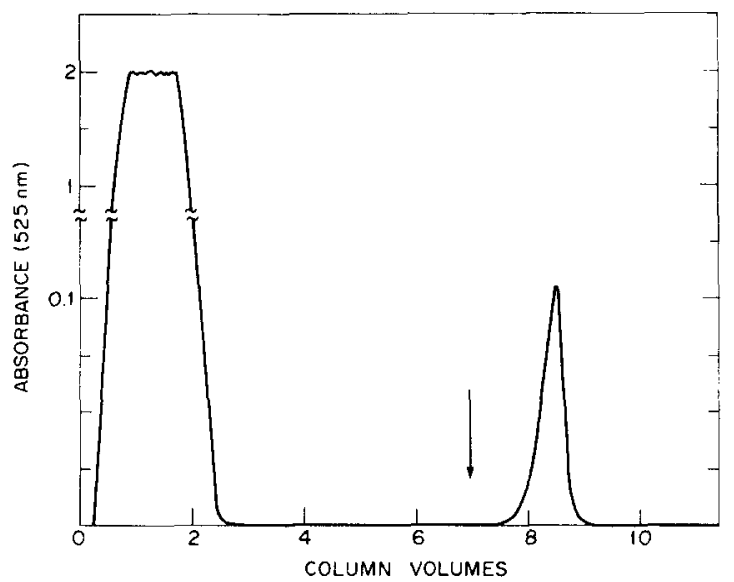

Fig. 1. Chromatography of chondroitinase-digested proteoglycan on Sepharose-HA. Proteoglycan $(250 \mathrm{mg}$ ) from bovine nasal cartilage was digested with chondroitinase ABC and chromatographed on a $1.5 \times 25 \mathrm{~cm}(44 \mathrm{ml})$ column of Sepharose-HA as described under Materials and Methods. The column was washed with $0.5 \mathrm{M} \mathrm{GuHCl} / 0.05 \mathrm{M}$ sodium acetate, $\mathrm{pH}$ 5.8. At the point indicated by the arrow, the concentration was increased to $4 \mathrm{M} \mathrm{GuHCl}$. The elution of the column was monitored by hexuronic acid analysis. 


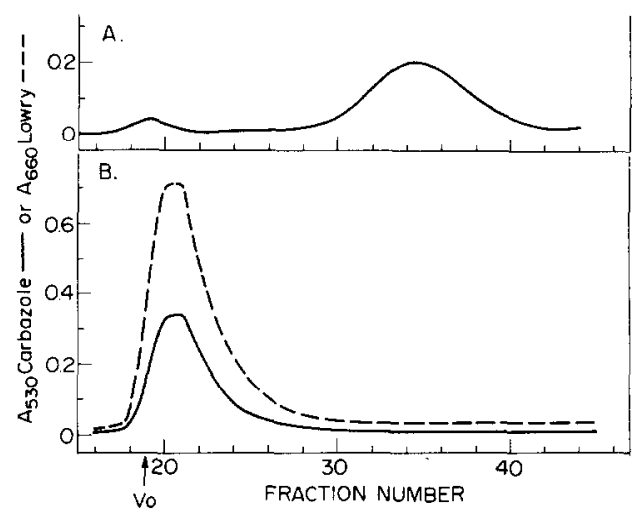

FIG. 2. Gel chromatography of protein-keratan sulfate core and protein-keratan sulfate core-HA complex on Sepharose 2B. A $0.8 \times 135 \mathrm{~cm}$ column of Sepharose 2B was eluted with $0.5 \mathrm{M}$ sodium acetate, $\mathrm{pH} 7.0$. Fraction volumes were $1.35 \mathrm{ml}$. The elution of hexuronic acid ( - ) was monitored by the automated carbazole assay and protein (-- $)$ by the automated Lowry assay. (A) Affinity purified core, $3.1 \mathrm{mg}$, in $1 \mathrm{ml}$ of $0.5 \mathrm{M}$ sodium acetate, $\mathrm{pH} 7.0$, was chromatographed. (B) Affinity purified core, $2.4 \mathrm{mg}$, and $100 \mu \mathrm{g}$ of $\mathrm{HA}$ in $1 \mathrm{ml}$ of $0.5 \mathrm{M}$ sodium acetate $\mathrm{pH} 7.0$, were incubated at $25^{\circ} \mathrm{C}$ for $1 \mathrm{~h}$ and then chromatographed.

a resultant increase in hydrodynamic volume. It should be noted that all of the affinity-purified core binds to free HA. In contrast, only $70 \%$ of the core isolated by gel chromatography interacts with HA (11). Inactive core molecules evidently do not bind to the affinity matrix. Thus, it appears that the chromatographic isolation of protein-keratan sulfate core with Sepharose-HA is dependent on the specific interaction through the HAbinding site and is not the result of nonspecific binding to the anionic groups of the HA-substituted beads.

Only a small fraction of undigested proteoglycan binds to Sepharose-HA. This material, which interacts with the affinity matrix, is believed to consist of small proteoglycans ${ }^{2}$ similar to those described by Heinegård (27). These results suggest that the majority of the proteoglycan molecules are too bulky to interact with the immobilized HA.

\section{Binding of ${ }^{125}$ I-Labeled Protein-Keratan Sulfate Core to Sepharose $-H A$}

To further assess the specificity of the interaction between core and immobilized HA, core was labeled with ${ }^{125} \mathrm{I}$ and its binding to Sepharose-HA was studied under equilibrium conditions. As shown in Fig. 3, ${ }^{125}$ I-labeled core bound to Sepharose-HA rapidly, reaching $85 \%$ of the

${ }^{2}$ J. E. Christner, M. L. Brown, and D. D. Dziewiatkowski, unpublished observations. 


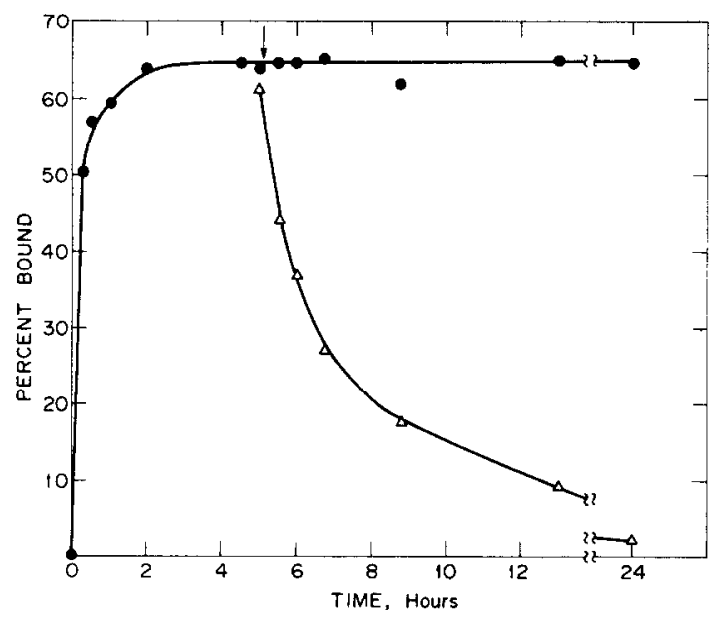

FIG. 3. Binding of the ${ }^{125}$ I-labeled protein-keratan sulfate core to Sepharose-HA and displacement as a function of time. The reaction mixtures contained $40 \mathrm{mg}$ of Sepharose-HA (containing $4 \mu \mathrm{g}$ of bound $\mathrm{HA})$ and ${ }^{125} \mathrm{I}$-labeled core $\left(2 \times 10^{4} \mathrm{cpm}\right)$ in $0.5 \mathrm{ml}$ of $0.05 \mathrm{M}$ sodium phosphate $/ 0.15 \mathrm{M} \mathrm{NaCl}, \mathrm{pH} 7.0$, containing $0.01 \%$ bovinc serum albumin. The suspensions were agitated by shaking at $25^{\circ} \mathrm{C}$ for the indicated time periods and the extent of binding was determined as given in the text. At the time point indicated by the arrow, $25 \mu \mathrm{l}$ of $\mathrm{H}_{2} \mathrm{O}(\bullet)$ or $22.5 \mu \mathrm{g}$ of $\mathrm{HA}$ dodecasaccharide $(\triangle)$ dissolved in $25 \mu \mathrm{l}$ of $\mathrm{H}_{2} \mathrm{O}$ was added to separate incubation mixtures. The extent of binding was determined at the indicated time intervals.

maximum level in $15 \mathrm{~min}$. In contrast, the displacement of the core by HA dodecasaccharide was much slower. These results are similar to those obtained by Hascall and Heinegård (11) for the binding of proteoglycan to $\mathrm{HA}$ and its displacement by HA oligosaccharides as measured by the viscosimetric method.

The fraction of ${ }^{125} I$ label bound to Sepharose-HA decreased with increasing total core concentration (Fig. 4). These results indicate that unlabeled core competes with its labeled counterpart for binding to immobilized HA. The inset of Fig. 4 displays the data in reciprocal form from which the binding capacity and binding constant can be derived. Each core molecule occupies 8 to 10 disaccharide units along the HA polysaccharide chain (11). The expected binding capacity of $1 \mathrm{~g}$ of substituted beads containing $0.21 \mu \mathrm{mol}$ of covalently coupled uronic acid is approximately $0.02 \mu \mathrm{mol}$ or $9 \mathrm{mg}$ of core of molecular weight $4.5 \times 10^{5}$ (1). This value is only threefold greater than that obtained experimentally. The relatively high capacity and binding constant values suggest that the immobilized HA is readily accessible to the core molecules in solution.

The ${ }^{125}$ I-labeled core also could be displaced from the affinity matrix by HA deca- and dodecasaccharides (Fig. 5). When HA at a concentra- 
tion equivalent to $2 \mu \mathrm{M}$ uronic acid was added to the reaction mixture which contained $20 \mu \mathrm{M}$ insolubilized uronic acid, the core binding was decreased to $50 \%$ of the control value. Taking into account that about $30 \%$ of the immobilized polysaccharide is accessible to the solution, the results indicate that $\mathrm{HA}$ in the soluble and insoluble phases has similar affinities for the HA-binding site. Octasaccharide at a high concentration ( $25 \mu \mathrm{M}$ uronic acid) inhibited the binding only $8 \%$ while chondroitin had little or no effect (Fig. 5). Hardingham and Muir (15) and Hascall and Heinegård (11) previously demonstrated that HA deca- and dodecasaccharides inhibited the interaction between proteoglycan and HA while the octasaccharide did not. Furthermore, Hascall and Heinegård (11) showed that the inhibition of core-HA interaction as detected by gel permeation chromatography exhibited a similar specificity and that chondroitin was ineffective in competing for the HA-binding site. In other experiments it was shown that HA decasaccharide, which was modified by esterification of carboxyl groups on the glucuronic acid residues, did not displace the ${ }^{125}$ I-labeled core. The elimination of competition by blockage of the oligosaccharide carboxyl groups is consistent with pre-

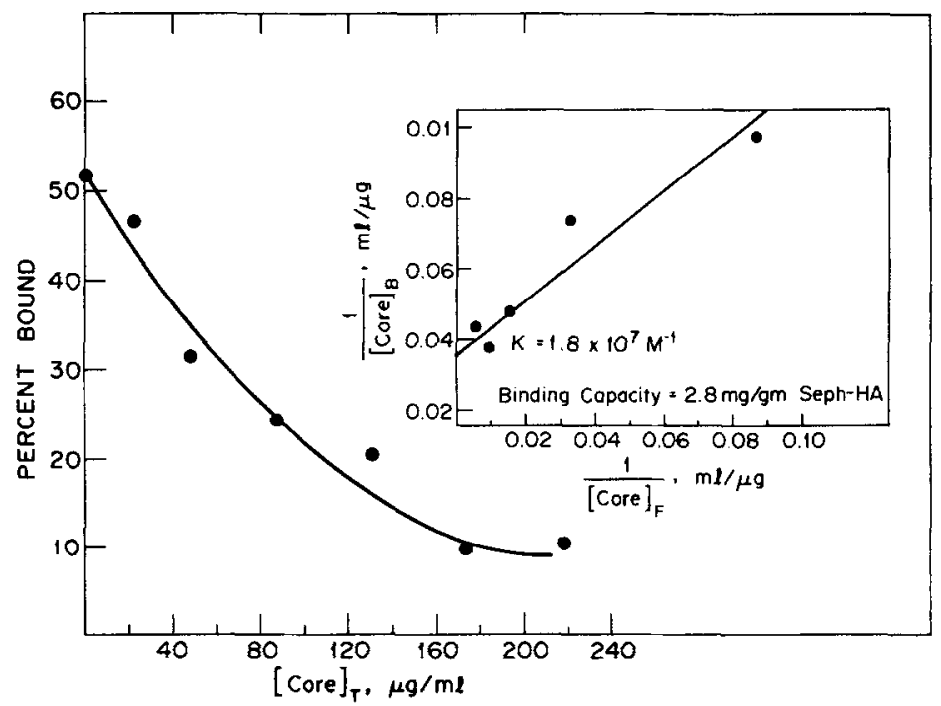

FIG. 4. Displacement of the ${ }^{125}$ I-labeled protein-keratan sulfate core from Sepharose-HA by unlabeled protein-keratan sulfate core. The reaction mixtures contained ${ }^{125}$ I-labeled core $\left(1.8 \times 10^{4} \mathrm{cpm}\right)$, the indicated amounts of unlabeled core, and $5 \mathrm{mg}$ of Sepharose-HA (containing $0.5 \mu \mathrm{g}$ of $\mathrm{HA}$ ) in a total volume of $0.5 \mathrm{ml}$ of $0.05 \mathrm{M}$ sodium phosphate $/ 0.15 \mathrm{M}$ $\mathrm{NaCl}, \mathrm{pH} 7.0$, containing $0.01 \%$ bovine serum albumin. The mixtures were agitated at $25^{\circ} \mathrm{C}$ for $16 \mathrm{~h}$ and the extent of binding was determined as described in the text. [Core $]_{T}$ : Total concentration of core; $[\text { Core }]_{B}$ : concentration of core bound to Sepharose-HA; [Core $]_{F}$ : concentration of free core. 


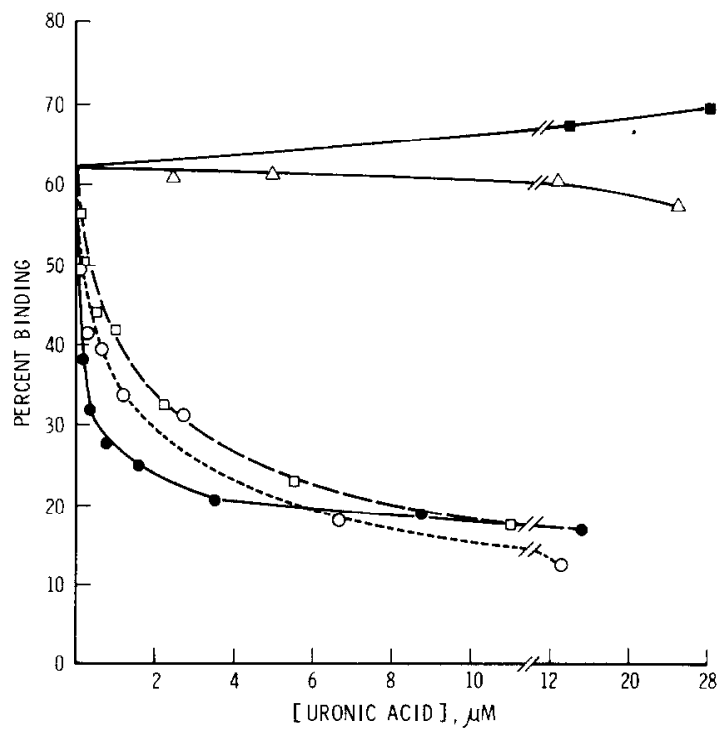

FIG. 5. Displacement of ${ }^{125}$ I-labeled protein-keratan sulfate core from Sepharose-HA by $\mathrm{HA}$, oligosaccharides of $\mathrm{HA}$, and chondroitin. The reaction mixtures contained $40 \mathrm{mg}$ of Sepharose-HA (containing $11.7 \mathrm{nmol}$ of bound uronic acid), ${ }^{125}$ I-labeled core $\left(1.8 \times 10^{4}\right.$ $\mathrm{cpm}$ ), and the indicated amounts of poly- and oligosaccharides in $0.55 \mathrm{ml}$ of $0.05 \mathrm{M}$ sodium phosphate $/ 0.15 \mathrm{M} \mathrm{NaCl}, \mathrm{pH} 7.0$, containing $0.01 \%$ bovine serum albumin. The mixtures were agitated by shaking for $4 \mathrm{~h}$ and the extent of binding was determined as described in the text. The polysaccharides used were HA $(O)$; HA dodecasaccharide $(O)$, decasaccharide $(\square)$, and octasaccharide $(\triangle)$; and chondroitin ( $\square$ ).

vious results (28) which showed that the methyl ester derivative of HA decasaccharide did not inhibit proteoglycan-HA interaction. The strict dependence of the inhibition on oligosaccharide chain length and composition strongly supports the specificity of the interaction between proteinkeratan sulfate core and Sepharose-HA.

The current model assumes that cartilage proteoglycan aggregates are stabilized by link proteins which interact with both the HA and the proteoglycan (11-14). Although interaction between link proteins and HA has been demonstrated $(11,29)$, nothing is known about the requirements of polysaccharide chain size and composition for the complex formation. The competitive binding studies demonstrated that the HA-substituted beads are useful for measuring the affinity and specificity of the interaction of protein core and HA. Presumably, they also could be used to elucidate the details of the link protein-HA aggregation process.

Hardingham and Adams (30) recently developed a sensitive assay for the determination of hyaluronic acid in cartilage. This assay, which requires $1-20 \mu \mathrm{g}$ of $\mathrm{HA}$, is dependent on the formation of large aggregates 
between the HA and cartilage proteoglycans which are detected by gel permeation chromatography. Using the competitive binding method described in the present report, $0.01 \mu \mathrm{g}$ of HA could be measured by a relatively simple procedure.

\section{ACKNOWLEDGMENTS}

This work was supported by the National Institutes of Health (Grant No. DE-0273I). We are grateful to Steven R. Hensel for skillful technical assistance.

\section{REFERENCES}

1. Hascall, V. C., and Riolo, R. L. (1972) J. Biol. Chem. 247, 4529-4538.

2. Hopwood, J. J., and Robinson, H. C. (1974) Biochem. J. 141, 517-526.

3. Anderson, H. C., and Sajdera, S. W. (1971) J. Cell Biol. 49, 650-663.

4. Sajdera, S. W., and Hascall, V. C. (1969) J. Biol. Chem. 244, 77-87.

5. Gregory, J. D., Sajdera, S. W., Hascall, V. C., and Dziewiatkowski, D. D. (1970) in Chemistry and Molecular Biology of the Intercellular Matrix (Balazs, E. A., ed.), Vol. 2, pp. 843-849, Academic Press. New York.

6. Franek, M. D., and Dunstone, J. R. (1967) J. Biol. Chem. 242, 3460-3467.

7. Pita, J. C., and Müller, F. J. (1973) Biochemistry 12, 2656-2665.

8. Hascall, V. C., and Sajdera, S. W. (1969) J. Biol. Chem. 244, 2384-2396.

9. Heinegård, D. (1972) Biochim. Biophys. Acta. 285, 181-192.

10. Hardingham, T. E., and Muir, H. (1972) Biochim. Biophys. Acta. 279, 401-405.

11. Hascall, V. C., and Heinegård, D. (1974) J. Biol. Chem. 249, 4242-4249.

12. Gregory, J. D. (1973) Biochem. J. 133, 383-386.

13. Heinegård, D., and Hascall, V. C. (1974) J. Biol. Chem. 249, 4250-4256.

14. Rosenberg, L., Margolis, R., Wolfenstein-Todel, C., Pal, S., and Strider, W. (1975) in Extracellular Matrix Influences on Gene Expression (Slavkin, H. C., and Greulich, R. C., eds.), pp. 415-421, Academic Press, New York.

15. Hardingham, T. E., and Muir, H. (1973) Biochem. J. 135, 905-908.

16. Christner, J. E., Brown, M. L., and Dziewiatkowski, D. D. (1977) Fed. Proc. 36, 748.

17. Oegema, T. E., Hascall, V. C., and Dziewiatkowski, D. D. (1975) J. Biol. Chem. 250, 6151-6159.

18. Swann, D. A. (1968) Biochim. Biophys. Acta. 156, 17-30.

19. Cleland, R. L., and Wang, J. L. (1970) Biopolymers 9, 799-810.

20. David, G. S., and Reisfeld, R. A. (1974) Biochemistry 13, 1014-1021.

21. Heinegård, D. (1973) Chem. Scr. 4, 199-201.

22. Spackman, D. H., Stein, W. H., and Moore, S. (1958) Anal. Chem. 30, 1190-1206.

23. Hascall, V. C., Riolo, R. L., Hayward, J., Jr., and Reynolds, C. C. (1972) J. Biol. Chem. 247, 4521-4528.

24. Wilchek, M., and Miron, T. (1974) Mol. Cell. Biochem. 4, 181-187.

25. Bitter, T., and Muir, H. (1962) Anal. Biochem. 4, 330-334.

26. Borch, R. F., and Durst, H. D. (1969) J. Amer. Chem. Soc. 91, 3996-3997.

27. Heinegård, D. (1977) J. Biol. Chem. 252, 1980-1989.

28. Christner, J. E., Brown, M. L., and Dziewiatkowski, D. D. (1977) Biochem. J. 167, 711-716.

29. Oegema, T. R., Brown, M., and Dziewiatkowski, D. D. (1977) J. Biol. Chem. 252, 6470-6477.

30. Hardingham, T. E., and Adams, P. (1976) Biochem. J. 159, 143-147. 